\title{
Thalassemia review: features, dental considerations and management
}

Nawal Helmi ${ }^{1}$, Mawahib Bashir ${ }^{2}$, Ayesha Shireen ${ }^{3}$, Iffat Mirza Ahmed ${ }^{4}$

${ }^{1}$ Ph.D., Assistant Professor, Biochemistry Department, College of Science, King Abdul Aziz University, Jeddah, Saudi Arabia

${ }^{2}$ MD Pathology, Assistant Professor, Basic Science Department, Al-Farabi College of Dentistry \& Nursing, Jeddah, Saudi Arabia

${ }^{3}$ MDS Oral Medicine \& Radiology, Lecturer, Oral \& Maxillofacial Surgery Department, Al-Farabi College of Dentistry \& Nursing, Jeddah, Saudi Arabia

${ }^{4} \mathrm{Ph}$.D. Student of Clinical Research, Lecturer, Oral \& Maxillofacial Surgery Department, Al-Farabi College of Dentistry \& Nursing, Jeddah, Saudi Arabia

\section{Type of article: Short review}

\begin{abstract}
Thalassemia is a genetic disorder that involves abnormal haemoglobin formation. The two main categories of thalassemia are alpha and beta thalassemia that are then divided into further subcategories. While some mild forms of thalassemia might even go unnoticed and only cause mild anaemia and iron deficiency problems in patients, other more severe forms of thalassemia can even result in death. Individuals with thalassemia can get treatment according to the level of severity of their condition. The main oral manifestations of thalassemia are Class II malocclusion, maxillary protrusion, high caries index, severe gingivitis. Any dental surgical procedure for such patients should be done under antibiotic cover and immediately after transfusion. Caution should be exercised in thalassemia patients due to complications related to compromised immunity and cardiovascular issues. Multidisciplinary approach involving dental surgeon, haematologist and orthodontist is the best advised approach.
\end{abstract}

Keywords: Thalassemia, Abnormal haemoglobin, Thalassemia dental treatment

\section{Introduction}

Thalassemia is a genetic disorder that involves abnormal haemoglobin formation (1-3). Haemoglobin comprises of alpha and beta 'chains' which, in a patient with thalassemia, are faulty as a result of which the haemoglobin produced is faulty. In a patient with thalassemia, problems arise because there is a lack of healthy haemoglobin that the body requires for it to become properly oxygenated. A patient with thalassemia, not only has lower levels of haemoglobin present in his or her bloodstream but also lacks good quality haemoglobin. At the same time, the patient's body continues trying to produce more red blood cells and haemoglobin. 4 However, since there is a genetic fault with the haemoglobin being produced in that individual's body, the new haemoglobin produced, causes further problems as an overproduction of unhealthy haemoglobin takes place. Individuals with thalassemia can be treated according to the level of severity of their condition $(2,4)$. While some mild forms of thalassemia might even go unnoticed and only cause mild anaemia and iron deficiency problems in patients, other more severe forms of thalassemia can even result in death. Most commonly, however, regular blood transfusions are used to treat patients with thalassemia since blood transfusions allow for these individuals' bloodstreams to be flooded with adequate amounts of 'healthy' and normal haemoglobin (2). The two main categories of thalassemia are alpha and beta thalassemia that are then divided into further subcategories $(2,5)$. The main cause behind thalassemia is always the defective synthesis of alpha or beta chains. 5 Alpha thalassemia occurs when one or more of the four alpha globin genes are either abnormal or not present in an individual. Beta thalassemia occurs when one or both Beta globin genes are either abnormal or are absent $(2,5)$. In most of the cases, mutations in the alpha or beta globin genes result

\section{Corresponding author:}

Iffat Mirza Ahmed, Al-Farabi College, Jeddah, Saudi Arabia. Tel: +966126735693, E-mail: iffatfarabi@gmail.com Received: November 21, 2016, Accepted: February 10, 2017, Published: March 2017 iThenticate screening: January 15, 2017, English editing: March 01, 2017, Quality control: March 06, 2017

(C) 2017 The Authors. This is an open access article under the terms of the Creative Commons Attribution-NonCommercialNoDerivs License, which permits use and distribution in any medium, provided the original work is properly cited, the use is non-commercial and no modifications or adaptations are made. 
in the development of thalassemia in the patient. Some of these gene mutations result in mild versions of thalassemia while others result in extremely severe forms of thalassemia $(1,2)$. The less severe forms of thalassemia, also known as thalassemia minor or thalassemia trait, mean that an individual carries a thalassemia gene but that the production of haemoglobin is enough in the individual's body for them to be considered as a healthy person $(1,2)$. In most cases, this can result in mild anaemia in an individual, which can also be mistaken for an iron deficiency (6). However, individuals who inherit this gene from their parents need to be very cautious when they have children of their own as the chances of their children inheriting more severe forms of thalassemia, increase significantly (7). The three types of thalassemia minor include alpha plus thalassemia trait which involves one of the four alpha genes to be missing, alpha zero thalassemia trait which involves two missing alpha haemoglobin genes, and beta thalassemia trait which involves the absence of one out of two beta haemoglobin genes $(2,3,5)$. However, there are a number of types of thalassemia that are more dangerous and severe than the aforementioned types. Firstly, there is beta thalassemia major (BTM) which basically involves the presence of two beta thalassemia genes in an individual (8). In this case, a significant portion of an individual's haemoglobin does not work. Another form of thalassemia that is milder than BTM is beta-thalassemia intermedia (BTI), which involves the presence of two thalassemia genes but also involves the presence of a higher amount of 'healthy' haemoglobin $(5,8)$. However, despite the fact that this form of thalassemia is less severe than BTM, it still requires continuous monitoring for life $(2,5,8)$. Hb $\mathrm{H}$ disease is another form of thalassemia where three of the four alpha haemoglobin genes are either missing completely or are abnormal (9). Patients with this type of thalassemia are usually anaemic as well, and require regular blood transfusions for life $(2,10,11)$. Hb Bart's is the most severe form of thalassemia and this condition arises when all four alpha haemoglobin genes are missing or are abnormal $(2,9)$. This form of thalassemia is so severe that even before birth, no haemoglobin can be made, as a result of which, the baby with this form of thalassemia dies in the womb (9). A family history of thalassemia increases the chances of an individual being affected by the disease (5, $10,12)$. However, the severity of the disease depends on which type of gene mutation has taken place, since some gene mutations result in more severe forms of thalassemia than others $(2,12)$. It must be noted that individuals with certain ancestries are more likely to develop thalassemia than others. Mostly, thalassemia affects individuals with Italian, Asian, African, Middle Eastern and Greek ancestry (2, 12). Studies have revealed that African American individuals tend to have lower haemoglobin levels than whites in general as a result of which the incidence of thalassemia among these individuals is also likely to be higher (13). In many cases, thalassemia is detectable six months after birth, if not during the pregnancy $(2,10,12)$. Symptoms associated with Haemoglobin H disease are usually identified during the individual's first two years of life $(9,14)$. Alpha thalassemia major, however, can be identified during the pregnancy since Haemoglobin production in the foetus does not start. In such cases, efforts can only be directed at taking the necessary precautions to avoid maternal complications that range from toxaemia to premature delivery and higher chances of delivery by caesarean sections $(5,7)$. The best option while dealing with thalassemia is to ensure that it is prevented, which can be done by checking both parents for the presence of any gene mutations before the couple decides to have a child $(5,8)$. Patients with thalassemia usually experience a loss of appetite, jaundice, an enlarged spleen or liver and several bone problems (3). Since thalassemia is most commonly treated with blood transfusions, this causes excess iron to build up in an individual's bloodstream (6). This excess iron can then cause several heart problems for the individual including irregular heartbeats, heart attacks and even death by heart failure $(2,6,10)$. Spleen enlargement also causes individuals to have their spleens removed as a result of which they are left more prone to catching infections (15). This is why patients with thalassemia are usually at a higher risk of infection, and death often results from these infections $(2,15)$. Finally, osteoporosis is another very common problem found in patients with thalassemia (16-18). Osteoporosis causes the bones to become brittle, and can break easily as a result of which thalassemia patients can experience a lot of discomfort pertaining to the bones and teeth (17). Patients with thalassemia can experience an enlargement of their upper jaw which is also known as the chipmunk face $(19,20)$. The chances of the migration and spacing of upper anterior teeth also increase, and there may be varying degrees of malocclusion in such patients too (21). Other than that, the teeth of patients who have thalassemia might be discoloured and have short crowns and roots (20). Individuals who have thalassemia have a higher rate of dental decay as compared to people who do not have thalassemia (20). Thalassemia patients' gums and the lining of their mouth become pale due to anaemia (2), they might also experience a sore or burning tongue due to folate deficiency $(10,22)$. Thalassaemic patients also experience painful swelling of salivary glands and a dry mouth which leads to reduced salivary protection (22). It has been seen from the previous studies that thalassaemic patients are prone to dental decay (20). This, at times, happens because the patients do not tend to regular dental care or hesitate to go to a dentist thinking they will not understand their condition; there have also been cases where the thalassaemic patients are more concerned with the serious medical complications of thalassemia and their teeth get neglected in the process $(20,22)$. Due to a higher rate of tooth decay and thalassaemic patients not paying much attention to their dental care through restorative dental 
treatments/fillings, there comes a stage when individuals will start experiencing pain in their teeth. It is then that thalassaemic patients try to get dental services in emergency (22). When patients start experiencing pain, this is when the dental decay has gone to an advanced stage. At this stage, there is a higher risk of abscess and infection traveling and spreading further into the tissues of the neck and face. When a patient reaches this stage, the more likely treatment of this is to extract the teeth of patients rather than provide fillings. As a result, thalassaemic patients lose more teeth $(10,22)$. In general, thalassemia causes problems at varying levels depending on the severity of the form of thalassemia. Patients with more serious forms of thalassemia experience a lot more difficulties with their daily lives as compared to those with milder forms of thalassemia (2).

\section{Discussion}

\subsection{Pathophysiology}

2.1.1. Pathophysiology of alpha thalassemia

The important factor involved in pathophysiology of alpha thalassemia is the reduced or absent synthesis of alpha globin chains which leads to an accumulation of otherwise normal beta globin chains in adults and gamma chains in the foetus. Instead of forming alpha/beta dimers that then form normal HbA tetramers (a2b2), the excess beta globin chains assemble into beta- 4 tetramers, called $\mathrm{HbH}(23,24)$. In the neonatal period, before beta globin chain synthesis reaches adult levels, excess unmatched gamma globin chains accumulate and form gamma-4 tetramers, called $\mathrm{Hb}$ Bart's (25). These two homotetramers are susceptible to oxidant injury $(23,25)$, and are functionally useless as oxygen delivery pigments because their affinity for oxygen is at least 10 times greater than $\mathrm{HbA}$; and the oxyhaemoglobin dissociation curve is not sigmoidal because there is no heme-heme interaction. The oxyhaemoglobin dissociation curves for $\mathrm{HbH}$ and $\mathrm{Hb}$ Bart's resemble that of myoglobin, a compound that holds but cannot deliver oxygen to the tissue (26). Causes of anaemia in alpha thalassemia is summarized in four components: 1) low haemoglobin $\mathrm{HbA}$ reduced or absent synthesis of alpha globin, 2) production of two abnormal haemoglobins $\mathrm{Hb}$ Bart's (gamma globin tetramers) and $\mathrm{HbH}$ (beta globin tetramers) because of insufficient numbers of alpha globin chain, 3) accumulation of excess unmatched non-alpha globin chains within red blood cells leads to Intracorpuscular haemolysis, and 4) Ineffective erythropoiesis.

\subsubsection{Pathophysiology of $\beta$ thalassemia}

A quantitative reduction of structurally normal $\beta$ globin chains result in $\beta$ thalassemia (27). They are caused by mutations that nearly all affect the $\beta$ globin locus and are extremely heterogeneous. Almost every possible defect affecting gene expression at transcription or post-transcriptional level, including translation, have been identified in $\beta$ thalassemia $(2,27)$. These genetic defects lead to a variable reduction in $\beta$ globin output ranging from a minimal deficit (mild $\beta+$ thalassemia alleles) to complete absence ( $\beta^{\circ}$ thalassemia) $(2,16,27)$. In $\beta$ thalassemia, the synthesis of normal $\alpha$ globin chains from the unaffected $\alpha$ globin genes continues as normal, resulting in the accumulation within the erythroid precursors of excess unmatched $\alpha$ globin $(2,8,27)$. The free $\alpha$ globin chains are not able to form viable tetramers and instead precipitate in the red cell precursors in the bone marrow, forming inclusion bodies, which are responsible for the extensive intramedullary destruction of the erythroid precursors and hence the ineffective erythropoiesis that underlies all $\beta$ thalassemia $(3,10,27)$. Causes of the anaemia in $\beta$ thalassemia occur in the presence of two phenomena: the first one is infective erythropoiesis and the second is the destruction of circulating red blood cells (haemolysis) $(5,8,10)$. The degree of haemolysis is directly correlated with extra alpha globin chain (28). Impaired deformability of RBCs alteration of affected RBCS surface, leads to removal of it by macrophages and oxidant injury to lipid and proteins of RBCs membrane by binding of oxidized alpha globin chains to the $\mathrm{RBC}$ membrane $(29,30)$. The two above-mentioned phenomena result in severe anaemia, marked erythroid hyperplasia in the bone marrow, resulting in bone marrow expansion, extramedullary haematopoiesis, hepatosplenomegaly. The main difference in pathophysiology between alpha and beta thalassemia is that, the excess beta or gamma globin chains in the alpha thalassemias, can form partially soluble but ineffective haemoglobin homotetramers. These homotetramers do not precipitate extensively until they are exposed to damaging effects, mostly oxidant in nature, in the circulation. In contrast, in the beta thalassemia's the excess unmatched alpha chains that accumulate cannot form alpha-4 tetramers; instead, they produce insoluble alpha aggregates even in very early marrow erythroid precursors, affecting membrane assembly and accelerating apoptosis (programmed cell death). Because of differences in the biochemical composition of aggregates between alpha globins and beta globins, the severity of the disease is less severe in alpha compared with beta thalassemia (31).

\subsection{Clinical Manifestations and management of thalassemia}

\subsubsection{Clinical Manifestations}

The main cause for oral manifestations of thalassemia is due to extreme compensatory hyperplasia of bone marrow, this in turn leads to expansion of marrow cavity. Facial features and oral manifestations are illustrated in Tables 1. 
http://www.ephysician.ir

Table 1. Facial features and oral manifestations of thalassemia

\begin{tabular}{|c|c|c|}
\hline \multicolumn{2}{|l|}{ Features } & Cause \\
\hline \multirow[t]{6}{*}{ Facial features } & Class II malocclusion & Maxillary protrusion, mandibular atrophy \\
\hline & Maxillary protrusion $(32,33)$ & $\begin{array}{l}\text { Early fusion of occipital sutures, } \\
\text { hyperplasia of anterior maxillofacial } \\
\text { structures }\end{array}$ \\
\hline & Lateral displacement of orbits (34) & Marrow overgrowth in maxillary bone \\
\hline & Chipmunk facies $(35,36)$ & $\begin{array}{l}\text { Malar prominence, saddle nose, frontal } \\
\text { bossing }\end{array}$ \\
\hline & Brodie syndrome (37) & $\begin{array}{l}\text { Mandibular arch is telescoped within the } \\
\text { maxillary arch }\end{array}$ \\
\hline & Pneumatisation of paranasal sinuses & $\begin{array}{l}\text { Hyperplasia of marrow in frontal, temporal } \\
\text { and facial bones }(33,34)\end{array}$ \\
\hline \multirow[t]{9}{*}{$\begin{array}{l}\text { Oral } \\
\text { manifestations }\end{array}$} & Malocclusion & $\begin{array}{l}\text { Maxillary protrusion, increased overjet, } \\
\text { anterior open bite }\end{array}$ \\
\hline & High caries index (33) & $\begin{array}{l}\text { Poor oral hygiene, less phosphorous and } \\
\text { IgA in saliva }\end{array}$ \\
\hline & Mucosal pallor, atrophic glossitis & Decreased haemoglobin levels \\
\hline & Severe gingivitis & If splenectomy done (35) \\
\hline & Inflammation of salivary glands & Iron deposits \\
\hline & Dark coloured gingiva & High ferritin levels in blood \\
\hline & Thin mandibular cortex (33) & Marrow proliferation, expansion of medulla \\
\hline & Multiple diastemas & \\
\hline & Roots- short and spike shaped, taurodontism (33) & \\
\hline
\end{tabular}

\subsubsection{Management of thalassaemic patients}

Before beginning the treatment, the following should be ascertained: 1) type of thalassemia: major, minor or intermedia, 2) present haemoglobin level of the patient, and 3) ddegree of iron overload in the body. Repeated transfusions increase the total body iron load resulting in complications, therefore assessment of iron overload should be done periodically: 1) elative organ involvement with iron, 2) chelators administered to the patient (patients receiving regular transfusions need to be on chelation therapy to help excrete excess iron), 3) presence or absence of splenomegaly (hypersplenism increases the need for blood transfusions). If the hypersplenism is accompanied with leucopenia and thrombocytopenia, splenectomy may be the treatment of choice, 4) history of splenectomy, and 5) overall patient prognosis and life expectancy. There are also dental considerations for thalassemia. Any invasive procedure in thalassemia patients should be done under antibiotic cover and immediately after transfusion. Liver function and coagulation tests should be done before dental procedures are carried out. Orofacial defects and malocclusions in less severe types of thalassemia can be treated surgically followed by orthodontic treatment for alignment of teeth. Less severe malocclusions can be corrected by orthodontic treatment at an early age. Prescription of hepatotoxic drugs should be given cautiously. Tetracycline, metronidazole and erythromycin estolate should be avoided. Paracetamol is a safe alternative to NSAIDS and aspirin. Sedation or anaesthesia may be used during dental treatment of thalassemia patients for better control and cooperation. Caution should be exercised in thalassemia patients due to complications related to compromised immunity, liver function, splenectomy and cardiovascular issues. Multidisciplinary approach involving dental surgeon, haematologist and orthodontist should be practiced.

\section{Acknowledgments:}

The authors thank King Abdul Aziz University and Al-Farabi College of Dentistry \& Nursing, Jeddah for their help in this review article.

\section{Conflict of Interest:}

There is no conflict of interest to be declared.

Authors' contributions:

All authors contributed to this project and article equally. All authors read and approved the final manuscript. 


\section{References:}

1) Vij R, Machado RF. Pulmonary complications of hemoglobinopathies. Chest. 2010; 138(4): 973-83. doi: 10.1378/chest.10-0317. PMID: 20923801.

2) Beck WS. Hematology. USA: The Massachusetts Institute of Technology; 1998.

3) Joly P, Pondarre C, Badens C. [Beta-thalassemias: molecular, epidemiological, diagnostical and clinical aspects]. Ann Biol Clin (Paris). 2014; 72(6): 639-68. doi: 10.1684/abc.2014.1015. PMID: 25486662.

4) Bernaudin F, Verlhac S, Chevret S, Torres M, Coic L, Arnaud C, et al. G6PD deficiency, absence of alphathalassemia, and hemolytic rate at baseline are significant independent risk factors for abnormally high cerebral velocities in patients with sickle cell anemia. Blood. 2008; 112(10): 4314-7. doi: 10.1182/blood2008-03-143891. PMID: 18772456.

5) Muncie HL Jr, Campbell J. Alpha and beta thalassemia. Am Fam Physician. 2009; 80(4): 339-44. PMID: 19678601.

6) Habibian N, Alipour A, Rezaianzadeh A. Association between Iron Deficiency Anemia and Febrile Convulsion in 3- to 60-Month-Old Children: A Systematic Review and Meta-Analysis. Iran J Med Sci. 2014; 39(6): 496-505. PMID: 25429171, PMCID: PMC4242983.

7) Aristizabal A, Merino S, Catediano E, Sasieta M, Aragues P, Navajas A. [Clinical consequences of alphathalassemia in the Basque Country, Spain. Impact of neonatal screening]. An Pediatr (Barc). 2015; 83(2): 85-8. doi: 10.1016/j.anpedi.2014.10.014. PMID: 25483992.

8) Galanello R, Origa R. Beta-thalassemia. Orphanet J Rare Dis. 2010; 5: 11. doi: 10.1186/1750-1172-5-11. PMID: 20492708 , PMCID: PMC2893117.

9) Chui DH. Alpha-thalassemia: Hb H disease and Hb Barts hydrops fetalis. Ann N Y Acad Sci. 2005; 1054: 25-32. doi: 10.1196/annals.1345.004. PMID: 16339648.

10) Harteveld CL, Higgs DR. $\alpha$-thalassaemia. Orphanet J Rare Dis. 2010; 5: 13. doi: 10.1186/1750-1172-5-13.

11) Leecharoenkiat K, Sornjai W, Khungwanmaythawee K, Paemanee A, Chaichana C, Roytrakul S, et al. Comparative Plasma Protein Profiling of Hemoglobin H Disease. Dis Markers. 2014; 2014. doi: $10.1155 / 2014 / 340214$.

12) Verma IC, Saxena R, Kohli S. Past, present \& future scenario of thalassaemic care \& control in India. Indian J Med Res. 2011; 134: 507-21. PMID: 22089615, PMCID: PMC3237251.

13) Maradiegue A, Edwards QT. An overview of ethnicity and assessment of family history in primary care settings. J Am Acad Nurse Pract. 2006; 18(10): 447-56. doi: 10.1111/j.1745-7599.2006.00156.x. PMID: 16999709.

14) Poyart C, Baudin V, Pagnier J. [Molecular engineering of hemoglobin for transfusion]. Rev Fr Transfus Hemobiol. 1992; 35(6): 417-24. doi: 10.1016/S1140-4639(05)80148-0. PMID: 1288540.

15) Jankulovski N, Antovic S, Kuzmanovska B, Mitevski A. Splenectomy for haematological disorders. Prilozi. 2014; 35(1): 181-7. PMID: 24798604.

16) Baldini M, Marcon A, Cassin R, Ulivieri FM, Spinelli D, Cappellini MD, et al. Beta-thalassaemia intermedia: evaluation of endocrine and bone complications. Biomed Res Int. 2014; 2014: 174581. doi: 10.1155/2014/174581. PMID: 25110660, PMCID: PMC4109222.

17) Rossi F, Perrotta S, Bellini G, Luongo L, Tortora C, Siniscalco D, et al. Iron overload causes osteoporosis in thalassemia major patients through interaction with transient receptor potential vanilloid type 1 (TRPV1) channels. Haematologica. 2014; 99(12): 1876-84. doi: 10.3324/haematol.2014.104463. PMID: 25216685, PMCID: PMC4258755.

18) De Sanctis V, Soliman AT, Elsedfy H, Yassin M, Canatan D, Kilinc Y, et al. Osteoporosis in thalassemia major: an update and the I-CET 2013 recommendations for surveillance and treatment. Pediatr Endocrinol Rev. 2013; 11(2): 167-80. PMID: 24575552.

19) Singh J, Singh N, Kumar A, Kedia NB, Agarwal A. Dental and periodontal health status of Beta thalassemia major and sickle cell anemic patients: a comparative study. J Int Oral Health. 2013; 5(5): 53-8. PMID: 24324305, PMCID: PMC3845285.

20) Hattab FN. Mesiodistal crown diameters and tooth size discrepancy of permanent dentition in thalassemic patients. J Clin Exp Dent. 2013; 5(5): e239-44. doi: 10.4317/jced.51214. PMID: 24455089, PMCID: PMC3892265.

21) Hattab FN. Patterns of physical growth and dental development in Jordanian children and adolescents with thalassemia major. J Oral Sci. 2013; 55(1): 71-7. doi: 10.2334/josnusd.55.71. PMID: 23485604.

22) Luglie PF, Campus G, Deiola C, Mela MG, Gallisai D. Oral condition, chemistry of saliva, and salivary levels of Streptococcus mutans in thalassemic patients. Clin Oral Investig. 2002; 6(4): 223-6. doi: 10.1007/s00784-002-0179-y. PMID: 12483237. 
23) Gabuzda TG. Hemoglobin H and the red cell. Blood. 1966; 27(4): 568-79. PMID: 5326597.

24) Nathan DG, Gunn RB. Thalassemia: the consequences of unbalanced hemoglobin synthesis. Am J Med. 1966; 41(5): 815-30. doi: 10.1016/0002-9343(66)90039-8. PMID: 5332176.

25) Lehmann H. Different types of alpha-thalassaemia and significance of haemoglobin Bart's in neonates. Lancet. 1970; 1(7663): 78-80. doi: 10.1016/S0140-6736(70)92645-0. PMID: 4193365.

26) Rigas DA, Koler RD. Decreased erythrocyte survival in hemoglobin H disease as a result of the abnormal properties of hemoglobin H: the benefit of splenectomy. Blood. 1961; 18: 1-17. PMID: 13741593.

27) Weatherall DJ, Clegg JB. The Thalassaemia Syndromes.4th ed. Oxford: Blackwell Science; 2001.

28) Vigi V, Volpato S, Gaburro D, Conconi F, Bargellesi A, Pontremoli S. The correlation between red-cell survival and excess of alpha-globin synthesis in beta-thalassemia. Br J Haematol. 1969; 16(1): 25-30. doi: 10.1111/j.1365-2141.1969.tb00375.x. PMID: 4183531.

29) Schrier SL, Rachmilewitz E, Mohandas N. Cellular and membrane properties of alpha and beta thalassemic erythrocytes are different: implication for differences in clinical manifestations. Blood. 1989; 74(6): 2194 202. PMID: 2804358.

30) Polliack A, Yataganas $X$, Rachmilewitz EA. Ultrastructure of the inclusion bodies and nuclear abnormalities in beta-thalassemic erythroblasts. Ann N Y Acad Sci. 1974; 232(0): 261-82. doi: 10.1111/j.1749-6632.1974.tb20591.x. PMID: 4370535.

31) Yuan W, Yufit T, Li L, Mori Y, Chen SJ, Varga J. Negative modulation of alpha1(I) procollagen gene expression in human skin fibroblasts: transcriptional inhibition by interferon-gamma. J Cell Physiol. 1999; 179(1): 97-108. doi: 10.1002/(SICI)1097-4652(199904)179:1<97::AID-JCP12>3.0.CO;2-E. PMID: 10082137.

32) Cutando Soriano A, Gil Montoya JA, López-González Garrido Jde D. Thalassemias and their dental implications. Med Oral. 2002; 7(1): 36-40, 41-5. PMID: 11788807.

33) Madhok S, Madhok S. Dental considerations in Thalassemic patients. Journal of Dental and Medical Sciences. 2014; 13(6): 57-62.

34) Trent RJ. Diagnosis of the haemoglobinopathies. Clin Biochem Rev. 2006; 27(1): 27-38. PMID: 16886045, PMCID: PMC1390791.

35) Tunaci M, Tunaci A, Engin G, Ozkorkmaz B, Dinçol G, Acunaş G, et al. Imaging features of thalassemia. Eur Radiol. 1999; 9: 1804-09. doi: 10.1007/s003300050926. PMID: 10602954.

36) Kharsa MA. Orthodontic Characteristics of Thalassemia Patients. Orthod Cyber Journal. 2008.

37) Adeyemo TA, Adeyemo WL, Adediran A, Akinbami AJ, Akanmu AS. Orofacial manifestations of hematological disorders: Anemia and hemostatic disorders. Indian J Dent Res. 2011; 22(3): 454-61. doi: 10.4103/0970-9290.87070. PMID: 22048588. 